\title{
Caracterização físico-química de qualidade da água de coco anão verde industrializada
}

\author{
Physical and chemical analysis physical of coconut water stored \\ Suziane Alves Josino Lima ${ }^{1}$, Antonio Vitor Machado ${ }^{2}$, Monica Tejo Cavalcanti ${ }^{3}$, Dyalla Ribeiro de Araújo ${ }^{4}$
}

\begin{abstract}
Resumo A água de coco vem ganhando espaço no mercado como uma bebida de vasto potencial comercial, pois além de ser um produto natural, possui baixo teor calórico, considerável valor nutricional e apresenta aroma e sabor suaves e agradáveis. Apresentando-se como uma bebida leve, refrescante e pouco calórica, composta de água, açúcares, proteínas, vitaminas e sais minerais, sendo apresentada como possível substituta às bebidas utilizadas para reidratação após os exercícios físicos, cujas características são alteradas na pré, pós-colheita e após processada. Neste contexto este trabalho objetivou avaliar as características físico-químicas de qualidade da água de coco anão verde industrializadas e comercializada no sertão paraibano e cearense durante o armazenamento simulado. Foram coletadas e identificadas, amostras em duas unidades industriais, no dia de sua fabricação, sendo estas transportadas para análise de qualidade até o tempo de vida útil mercadológico, sendo utilizado um planejamento experimental fatorial com as variáveis temperatura $\left(2,7\right.$ e $\left.12^{\circ} \mathrm{C}\right)$ e tempo $(1,15$ e 30 dias $)$. Os parâmetros avaliados foram: turbidez, condutividade, viscosidade, $\mathrm{pH}$, sólidos solúveis totais, acidez total e ácido ascórbico. O binômio tempo $\mathrm{x}$ temperatura influenciou consideravelmente os parâmetros analisados durante o armazenamento, onde observou-se diminuição nos valores de $\mathrm{pH}$, vitamina $\mathrm{C}$, condutividade elétrica e sólidos solúveis totais para ambas as indústrias e aumentos simultâneos para as indústrias quanto aos parâmetros analisados de turbidez, viscosidade, e acidez total titulável. Sugere-se como forma de garantia da manutenção da qualidade da água de coco à implantação e monitoramento de Boas Práticas de Fabricação para as unidades produtoras.
\end{abstract}

Palavras chave: armazenamento, qualidade, água de coco

Abstract - Coconut water is becoming more popular in the market as a vast commercial potential drink, as well as being a natural product, has low calorie, considerable nutritional value and features soft and pleasant aroma and flavor. Presenting itself as a light, refreshing and low in calories drink, composed of water, sugars, proteins, vitamins and minerals, and is presented as a possible replacement to beverages used for rehydration after exercise, whose characteristics are altered in pre-, post- harvest and processed. Therefore, this study aimed to evaluate the physical and chemical characteristics of quality industrialized green dwarf coconut water and marketed in Paraíba and Ceará hinterland during the simulated storage. Were collected and identified samples in two industrial units on the date of its manufacture, which are transported to quality analysis until the time of marketing life, and using a factorial design with variable temperature $\left(2,7\right.$ and $\left.12{ }^{\circ} \mathrm{C}\right)$ and time $(1,15$ and 30 days). The parameters evaluated were: turbidity, conductivity, viscosity, $\mathrm{pH}$, total soluble solids, total acidity and ascorbic acid. The binomial time $\mathrm{x}$ temperature considerably influenced the parameters analyzed during storage, where there was a decrease in $\mathrm{pH}$, vitamin $\mathrm{C}$, electrical conductivity and total soluble solids for both industries and simultaneous increases for industries as the analyzed turbidity parameters, viscosity, and titratable acidity. It is suggested as a way of ensuring the maintenance of water quality coconut to the implementation and monitoring of Good Manufacturing Practices for the production units.

Keywords: storage, quality, coconutwater

\footnotetext{
*Autor para correspondência

Recebido para publicação em 10/01/2015; aprovado em 25/01/2015

${ }^{1}$ Mestre em Sistemas Agroindustriais, PPGSA-UFCG, Pombal-PB. E-mail: suzyalveslima@gmail.com

${ }^{2}$ Professor adjunto UFERSA E-mail: machadoav@ufersa.edu.br

${ }^{3}$ Professora adjunta CCTA/UATA/UFCG . E-mail: monicatejo@ @cta.ufcg.edu.br

${ }^{4}$ Professora adjunta IFCE/Campus Crato .E-mail: dialla@ifce.edu.br
} 


\section{INTRODUÇÃO}

O Brasil possui cerca de 280 mil hectares cultivados com coqueiro, distribuídos, praticamente, em todo o território nacional com produção equivalente a dois bilhões de frutos/ano, sendo os estados do nordeste os maiores produtores. As frutas tropicais, na maioria das vezes, não são cultivadas e nem processadas no Brasil e isto se deve, principalmente, à falta de infraestrutura e ao baixo nível de conhecimento técnico.

O consumo do coco verde no Brasil é crescente (entre 10 e $20 \%$ ao ano), com demanda suprida pelo comércio do fruto e, principalmente, pela extração e envasamento da água, o que envolve pequenas, médias e grandes empresas.

A água de coco é utilizada na cultura popular como substituto da água, como também para repor eletrólitos nos casos de desidratação (ARAGÃO et al., 2001). A partir da década de 1990, com a maior conscientização da população para os benefícios dos alimentos naturais, verificou-se um aumento da exploração do coqueiro anão com vistas à produção do fruto verde para o consumo de água (EMBRAPA, 2011).

Tradicionalmente, a água é comercializada dentro do próprio fruto, prática que envolve problemas relacionados a transporte, armazenamento e perecebilidade do produto, sendo sua industrialização de fundamental importância, pois permite o seu consumo em locais fora das regiões produtoras, visando diminuir o volume e o peso transportados e, consequentemente, os custos, bem como aumentar a sua vida de prateleira (AROUCHA et al., 2005).

A água do coco verde pode ser consumida tanto na forma in natura quanto processada. Os métodos de processamento empregados visam, essencialmente, inibir a ação enzimática e garantir a estabilidade microbiológica da água-de-coco após a abertura do fruto, mantendo o quanto possível suas características sensoriais originais (COSTA et al., 2005).

A fim de avaliar a qualidade da água de coco comercializada nos estados do Ceará e Paraíba, este trabalho teve como objetivo avaliar as qualidades físicas e físicoquímicas da água de coco armazenada nas condições preditas na legislação brasileira vigente.

\section{MATERIAL E MÉTODOS}

Utilizou-se como matéria prima água de coco anã verde produzida industrialmente e comercializada nos estados da Paraíba (Indústria A) e do Ceará (Indústria B), legalizada pelos órgãos de fiscalização, onde cada parcela, ou amostra, foi composta de quatro copos tipo PET transparente de 300 $\mathrm{mL}$, no dia de sua fabricação, sendo estas transportadas para os Laboratórios de Análise de Alimentos do Centro de Ciência e Tecnologia Agroindustrial da Universidade Federal de Campina Grande (UFCG), Campus Pombal - PB.

A definição das temperaturas de armazenamento do produto em estudo foi realizada de acordo com a legislação vigente (BRASIL, 2009), onde se determina temperatura máxima de armazenamento de $7{ }^{\circ} \mathrm{C}$.

Com isso, as amostras obtidas das indústrias foram armazenadas de acordo com o planejamento fatorial experimental $2^{2}+3$ pontos centrais, para avaliar quantitativamente a influência das variáveis de entrada temperatura $\left(2,7\right.$ e $\left.12{ }^{\circ} \mathrm{C}\right)$ e tempo de armazenamento $(1,15$ e 30 dias) sobre as respostas (qualidade do produto).

\section{Parâmetros avaliados}

\section{- Turbidez (NTU)}

A turbidez foi determinada por espectrofotometria a $610 \mathrm{~nm}$ (relativa à água destilada) em Turbidimetro Policontrol (AP 2000). Os valores de transmitância foram calculados de acordo com Campos et al. (1996).

\section{- Condutividade $\left(\mathrm{mS} / \mathrm{cm}^{-1}\right)$}

Determinado pelo método eletrométrico, utilisando condutivimetro LUCADEMA (modelo Mca 150). A análise de condutividade se baseia em medição direta ao contato do eletrodo com a amostra.

\section{- Viscosidade $\left(\mathrm{mm}^{2} / \mathrm{s}^{-1}\right)$}

Foi utilizado um viscosímetro marca DV-E (Viscometer Brookfield), utilizando cilindro de diâmetro externo de $100 \mathrm{~mm}$ (splindle de referência S2).

\section{- Potencial Hidrogeniônico (pH)}

Determinado pelo método potenciométrico, com $\mathrm{pH}$ metro LUCADEMA (modelo mPA-210). Seguido pelo método 017/IV do Instituto Adolfo Lutz (BRASIL, 2008).

\section{- Sólidos Solúveis Totais $\left({ }^{\circ}\right.$ Brix)}

$\mathrm{O}$ teor de sólidos solúveis totais expresso em ${ }^{\circ} \mathrm{Brix}$ foi determinado pelo método refratométrico, em refratômetro tipo REICHERTAR (200) segundo as normas analíticas do Instituto Adolfo Lutz (BRASIL, 2008).

\section{- Acidez Total Titulável (\%)}

A determinação de acidez titulável (AT), foi determinada pelo método acidimétrico pela titulação com hidróxido de sódio e expressa em g de ácido cítrico/100 mL descrito nas normas analíticas do Instituto Adolfo Lutz (BRASIL, 2008).

\section{- Ácido Ascórbico (mg/100g)}

$\mathrm{O}$ teor de ácido ascórbico (vitamina C) foi determinado segundo o método da AOAC (1997), no qual utilizou-se $2 \mathrm{~g}$ da amostra e $50 \mathrm{~mL}$ da solução de ácido oxálico a $1 \%$ (solução extratora) e se baseia na titulação da amostra, empregando-se 2,6 diclorofenol-indofenol sódio, que dá cor azul em solução alcalina e cor rósea em solução ácida. Os resultados foram expressos em mg de ácido ascórbico/100 g da amostra.

\section{- Cinzas (\%)}

O resíduo de minerais fixo (cinzas) foram determinadas pelo método gravimétrico por incineração em forno mufla (Q- 318S24) QUIMIS, a $500{ }^{\circ} \mathrm{C}$, conforme metodologia do Instituto Adolfo Lutz (BRASIL, 2008).

\section{- Proteínas (\%)}

O teor de proteína foi determinado através do método descrito pelo Instituto Adolfo Lutz (BRASIL, 2008) utilizando o fator de 6,25. 


\section{- Açúcares redutores (\%)}

$\mathrm{O}$ teor de açúcares redutores foi determinado pelo método de redução alcalina, descrito pelo Instituto Adolfo Lutz (BRASIL, 2008), e os resultados expressos em percentagem de glicose.

\section{RESULTADOS E DISCUSSÃO}

Na Tabela 1 estão apresentados os valores médios dos parâmetros de turbidez, condutividade elétrica, viscosidade, $\mathrm{pH}$, sólidos solúveis totais e acidez total das amostras de água de coco anão verde comerciais das indústrias $\mathrm{A}$ e $\mathrm{B}$.

Tabela 1 - Resultado da caracterização da água de coco anã verde produzida comercialmente

\begin{tabular}{lcccccc}
\hline \multicolumn{1}{c}{ Amostra } & $\mathbf{p H}$ & $\begin{array}{c}\text { ATT } \\
(\mathbf{g} \text { ác. cítrico/100 } \mathbf{~ m L})\end{array}$ & $\begin{array}{c}\text { SST } \\
(\circ \mathbf{B r i x})\end{array}$ & $\begin{array}{c}\text { Turbidez } \\
(\mathbf{N} . \mathbf{T} . \mathbf{U})\end{array}$ & $\begin{array}{c}\text { Condutividade } \\
\left(\mathbf{m S}_{\mathbf{c m}} \mathbf{- 1}\right)\end{array}$ & $\begin{array}{c}\text { Viscosidade } \\
\left(\mathbf{m m}^{\mathbf{2}} / \mathbf{s}^{-\mathbf{1}}\right)\end{array}$ \\
\hline Ind. A & $5,05^{\mathrm{a}}$ & $0,07^{\mathrm{a}}$ & $5,35^{\mathrm{a}}$ & $9,50^{\mathrm{b}}$ & $4,38^{\mathrm{a}}$ & $0,32^{\mathrm{a}}$ \\
Ind. B & $5,15^{\mathrm{a}}$ & $0,03^{\mathrm{a}}$ & $5,45^{\mathrm{a}}$ & $18,1^{\mathrm{a}}$ & $4,39^{\mathrm{a}}$ & $0,30^{\mathrm{a}}$ \\
\hline DMS & 0,30 & 0,13 & 1,85 & 6,63 & 3,56 & 0,48 \\
MG & 5,10 & 0,05 & 5,40 & 13,80 & 4,38 & 0,85 \\
CV\% & 1,39 & 54,7 & 7,97 & 11,14 & 18,84 & 14,22 \\
\hline
\end{tabular}

DMS - Desvio mínimo significativo; MG - Média geral; CV - Coeficiente de variação. Médias seguidas por letra distintas, minúsculas nas colunas e maiúsculas nas linhas diferem entre si pelo teste de Tukey $(\mathrm{p} \leq 0,05)$

As amostras avaliadas apresentam-se dentro dos padrões estabelecidos pela Instrução Normativa $\mathrm{n}^{\circ} 39$, de 22 de julho de 2009 (BRASIL, 2009), que estabelece pH mínimo de 4,3 para água de coco.

Rosa e Abreu (2000), encontram em frutos com 7 meses de idade na variedade anão verde valor de 4.91. Para Nery et al. (2002), a avaliação do pH é importante, pois o sabor doce e adstringência desejável são atingidos com $\mathrm{pH}$ próximos de 5,5, valores estes observados em frutos por volta dos sete meses de desenvolvimento de seis cultivares de coqueiro anão. $\mathrm{O}$ pH, da água de coco, varia pouco ao longo do desenvolvimento do fruto, se modifica com a maturação, aumentando no decorrer desta (PINHEIRO et al., 2005).

Os teores de sólidos solúveis totais das amostras mantiveram-se próximos do limite estabelecido pela legislação vigente, que estabelece máximo de 6,7 ( ${ }^{\circ}$ Brix), variando de 5,35 a 5,45 ( ${ }^{\circ}$ Brix), respectivamente, para as industrias A e B.

Para os valores médios do teor de acidez das amostras de água de coco, as mesmas, variaram entre 0,07 ( $\mathrm{g}$ de ác. cítrico/100 mL) para indústria A e 0,03 (g ác. cítrico/100 mL) para indústria B. A legislação (BRASIL, 2009) estabelece para acidez de água de coco, limites máximos e mínimos de $(0,18 \mathrm{~g} / 100 \mathrm{ml}$ e 0,06g/100 ml) respectivamente estando, portanto a indústria $\mathrm{B}$, apresentando abaixo do valor permitido. Silva et al. (2009), encontraram resultados superiores de teor de acidez próximos a 0,11 g/100 $\mathrm{mL}$.

A turbidez é definida, em termos práticos, como sendo a redução da transparência da água devido a presença de matéria em suspensão, que dependendo da concentração desta, podem alterar a cor da água. A turbidez dos produtos avaliados (indústria A - 9,5 N.T.U) e indústria B - 18,1 N.T.U) apresentaram próximos aos valores de 12,1 e 13 (N.T.
U) relatados por Silva et al., (2010), e de 7,8 e 13,8 (N.T.U) e Magalhães et al. (2005). Essa variação na turvação presente nas amostras de água de coco analisadas deve-se, provavelmente, pelo estádio de maturação dos frutos utilizados, onde quanto mais maduro for o fruto, maior tendência terá a sua água a apresentar turbidez (KWIATKOWSKI et al., 2012).

A condutividade elétrica e viscosidade das águas de coco estudadas não se diferenciaram estatisticamente entre si. A viscosidade de muitos líquidos, altera-se com mudanças da temperatura, altas temperaturas geralmente diminuem a viscosidade, porque diminui o atrito entre as moléculas.

$\mathrm{Na}$ Tabela 2 estão expressos os valores para o teor de vitamina $\mathrm{C}$, cinzas, proteínas e açúcares redutores nas amostras comercializadas pelas indústrias. Observa-se que as amostras analisadas não apresentaram diferenças significativas pelo teste de Tuckey a nível de 5\% de significância em nenhum parâmetro avaliado. A agua de coco analisada apresentou teor de vitamina $C$ variando entre 1,60 $(\mathrm{mg} / 100 \mathrm{~g})$ para indústria A e 1,25 (mg/ 100g) para indústria B. A possível causa da baixa concentração desse parâmetro pode ser devido a oxidação da água de coco durante a operação de coleta da água do fruto ou do processamento. A água de coco é pobre em proteínas, apresentando maior concentração com a maturidade no $11^{\circ}$ mês ao $12^{\circ}$ mês quando o teor de gordura se encontra mais presentes. Os traços de açúcares não redutores demonstram que as amostras encontram-se em estágio inicial de maturação, onde a frutose e a glicose (açúcares redutores) predominam, e quase não se encontra a sacarose (açúcar não redutor). Constatando que a colheita do fruto foi feita até o $7^{\circ}$ mês, fase ideal para comercialização de água de coco verde, pois se encontra uma maior quantidade de frutose livre (teor de doçura maior que a sacarose), tornando a água de coco anão verde mais doce.

Tabela 2 - Teor de vitamina C, cinzas, proteínas e açucares redutores na água de coco anão verde analisada

\begin{tabular}{lcccc}
\hline \multicolumn{1}{r}{ Amostra } & Vitamina C (mg/100g) & Cinzas (\%) & Proteínas (\%) & Açúcares Redutores \\
\hline Ind. A & $1,60^{\mathrm{a}}$ & $0,48^{\mathrm{a}}$ & $0,20^{\mathrm{a}}$ & $2,25^{\mathrm{a}}$ \\
Ind. B & $1,25^{\mathrm{a}}$ & $0,47^{\mathrm{a}}$ & $0,20^{\mathrm{a}}$ & $2,50^{\mathrm{a}}$ \\
\hline DMS & 2,80 & 0,04 & 0,43 & 0,77 \\
MG & 1,42 & 0,48 & 0,20 & 2,38 \\
CV\% & 45,61 & 1,88 & 0,50 & 7,48 \\
\hline
\end{tabular}

DMS - Desvio mínimo significativo; MG - Média geral; CV - Coeficiente de variação.Médias seguidas por letra distintas, minúsculas nas colunas e maiúsculas nas linhas diferem entre si pelo teste de Tukey $(\mathrm{p} \leq 0,05)$. 
O estudo de armazenamento da agua de coco comercializada pela indústria A está apresentado na Tabela 3. Os parâmetros tidos como respostas para o armazenamento da agua de coco foram $\mathrm{pH}$, turbidez, condutividade elétrica, teor de sólidos solúveis totais, acidez total, vitamina $\mathrm{C}$ e viscosidade.

Analisando as respostas para o planejamento experimental fatorial utilizado através da Análise de Variância (ANOVA), observou-se que só o parâmetro do teor de sólidos solúveis, tido como resposta para o armazenamento da agua de coco da indústria $\mathrm{A}$, foi o que apresentou $\mathrm{o}$ modelo significativo. Os dados foram analisados considerando o erro puro e um limite de confiança de $95 \%$. Nota-se que o coeficiente de determinação, R2 $=97,80 \%$, com equação para o modelo, $\mathrm{SST}\left({ }^{\circ} \mathrm{Brix}\right)=\mathbf{5 , 2 6}+0,058 \mathrm{X}_{1}+$ $\mathbf{0 , 0 4 4} \mathbf{X}_{2}-\mathbf{0 , 0 0 8} \mathbf{X}_{1} X_{2}$. Resposta $=\left(B_{0}+B_{1} X_{1}+B_{2} X_{2}+\right.$ $\mathrm{B}_{3} \mathrm{X}_{1} \mathrm{X}_{2}$ ), onde $\mathrm{X}_{1}$ é a temperatura de armazenamento e $\mathrm{X}_{2} \mathrm{O}$ tempo de armazenamento considerado.

Podemos observar a partir do diagrama de Pareto (Figura 1), que a interação entre as variáveis temperatura e tempo de armazenamento influenciou negativamente no teor de sólidos solúveis totais na amostra (efeito estimado de 9,60), assim como a temperatura (efeito estimado de -5,60). A partir da superfície de resposta gerada para o teor de sólidos solúveis totais na água de coco durante o armazenamento (Figura 2), observa-se que os valores médios foram de 5,50 $\left(^{\circ}\right.$ Brix), entre as temperaturas de 4 a $6{ }^{\circ} \mathrm{C}$ e tempo de 0 a 10 dias de armazenamento. Isso se deve aos processos metabólicos e danos microbiológicos que se aceleram, ocasionando assim a queda do ${ }^{\circ}$ Brix, com o avanço da temperatura.

Observa-se que temperaturas mais elevadas, favoreceram aumento destes sólidos até aproximadamente o quinto dia de armazenamento, enquanto, baixas temperaturas, favoreceram o aumento com o avanço do tempo de armazenamento.

Os demais parâmetros avaliados não apresentaram modelos significativos, porém, ao se avaliar alguns parâmetros isoladamente do modelo, foi observado que as amostras de água de coco apresentam valores médios de $\mathrm{pH}$ variando entre 4,10 e 5,80. O experimento 1 , equivalente a 1 dia de armazenamento a $2{ }^{\circ} \mathrm{C}$, obteve maior $\mathrm{pH}$ quando comparado aos demais experimentos e o experimento com 30 dias de armazenamento a $12{ }^{\circ} \mathrm{C}$ foi o que apresentou menor pH estando em desconformidade com a legislação vigente (BRASIL, 2009). Valores baixos de $\mathrm{pH}$ podem ser perigosos neste tipo de produto, pois pode levar ao desenvolvimento de alguns micro-organismos patogênicos, como por exemplo o e Clostridium botulinum com $\mathrm{pH}$ mínimo para multiplicação das cepas entre 4,8 e 5,0. A acidez observada na água de coco da indústria $\mathrm{A}$, após o primeiro dia de armazenamento foi bem acima do recomendado pela legislação, que estabelece para água de coco refrigerada, valores de acidez total titulável entre 0,06 g/100 mL e 0,18 g/mL (BRASIL, 2009).

A turbidez da água de coco armazenada no período de 30 dias foi bastante elevada quando comparada com menores tempos de armazenamento. A presença de sólidos em suspenção, ocorrido durante o armazenamento, pode ter ocasionado a turvação do produto. Vários estudos têm demonstrado que a viscosidade de um líquido é altamente influenciada por mudanças na temperatura, ocasionando perdas na qualidade do produto (OLIVEIRA; BARROS; ROSSI, 2009). Este comportamento foi observado no armazenamento testado, onde observa-se maior viscosidade em temperaturas de armazenamento mais elevadas.

Tabela 3 - Estudo de armazenamento da água de coco comercializada pela indústria A

\begin{tabular}{|c|c|c|c|c|c|c|c|c|c|}
\hline \multirow{3}{*}{ Exp. } & \multicolumn{2}{|c|}{ Variáveis } & \multirow{2}{*}{\multicolumn{7}{|c|}{ Respostas }} \\
\hline & $\begin{array}{c}\text { Temperatura } \\
\left({ }^{\circ} \mathrm{C}\right)\end{array}$ & $\begin{array}{c}\text { Tempo } \\
\text { [dia (s)] }\end{array}$ & & & & & & & \\
\hline & $\mathrm{X} 1$ & $\mathrm{X} 2$ & $\mathrm{pH}$ & $\begin{array}{l}\text { Turbidez } \\
\text { (N.T.U) }\end{array}$ & $\begin{array}{l}\text { Condutividade } \\
\left(\mathrm{mS} / \mathrm{cm}^{-1}\right)\end{array}$ & $\begin{array}{l}\mathrm{SST}^{*} \\
\left({ }^{\circ} \mathrm{Brix}\right)\end{array}$ & $\begin{array}{l}\text { ATT (g ác. } \\
\text { Cítrico/100 } \\
\mathrm{mL})\end{array}$ & $\begin{array}{c}\text { Vit. C } \\
(\mathrm{mg} / 100 \mathrm{~g})\end{array}$ & $\begin{array}{l}\text { Viscosidade } \\
\left(\mathrm{mm}^{2} / \mathrm{s}^{-1}\right)\end{array}$ \\
\hline 1 & 2 & 1 & $5,80^{\mathrm{a}}$ & $8,60^{d}$ & $4,10^{\mathrm{a}}$ & 5,40 & $1,50^{\mathrm{e}}$ & $1,10^{\mathrm{a}}$ & $0,32^{c}$ \\
\hline 2 & 12 & 1 & $5,10^{c}$ & $9,50^{\mathrm{d}}$ & $4,10^{\mathrm{a}}$ & 5,80 & $1,10^{\mathrm{e}}$ & $1,20^{\mathrm{a}}$ & $0,30^{\mathrm{c}}$ \\
\hline 3 & 2 & 30 & $5,40^{\mathrm{b}}$ & $114,00^{\mathrm{b}}$ & $3,80^{\mathrm{b}}$ & 6,10 & $3,30^{\mathrm{d}}$ & $0,70^{\mathrm{a}}$ & $0,60^{\mathrm{bc}}$ \\
\hline 4 & 12 & 30 & $4,10^{\mathrm{e}}$ & $248,50^{\mathrm{a}}$ & $3,30^{\mathrm{c}}$ & 4,20 & $11,10^{\mathrm{a}}$ & $0,60^{\mathrm{a}}$ & $0,81^{\mathrm{b}}$ \\
\hline 5 & 7 & 15 & $4,70^{\mathrm{d}}$ & $27,60^{\mathrm{c}}$ & $3,40^{\mathrm{c}}$ & 5,30 & $5,80^{\mathrm{c}}$ & $0,60^{\mathrm{a}}$ & $1,37^{\mathrm{a}}$ \\
\hline 6 & 7 & 15 & $4,70^{\mathrm{d}}$ & $24,60^{\mathrm{c}}$ & $3,50^{\mathrm{bc}}$ & 5,50 & $7,10^{\mathrm{b}}$ & $0,70^{\mathrm{a}}$ & $1,50^{\mathrm{a}}$ \\
\hline 7 & 7 & 15 & $4,60^{\mathrm{d}}$ & $25,30^{\mathrm{c}}$ & $4,10^{\mathrm{a}}$ & 5,50 & $6,00^{\mathrm{bc}}$ & $0,70^{\mathrm{a}}$ & $1,05^{\mathrm{ab}}$ \\
\hline
\end{tabular}

Médias seguidas por letra distintas, minúsculas nas colunas e maiúsculas nas linhas diferem entre si pelo teste de Tukey (p $\leq 0,05)$. Resposta em que o modelo se mostrou significativo.

Figura 1 - Diagrama de Pareto para o teor de sólidos solúveis totais da agua de coco armazenada

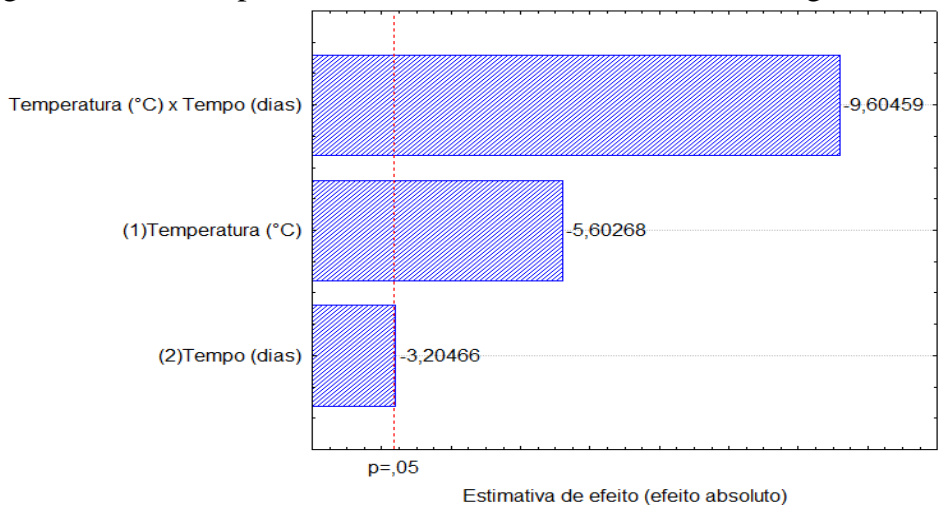


Figura 2 - Superfície de resposta para o teor de sólidos solúveis totais em agua de coco armazenada

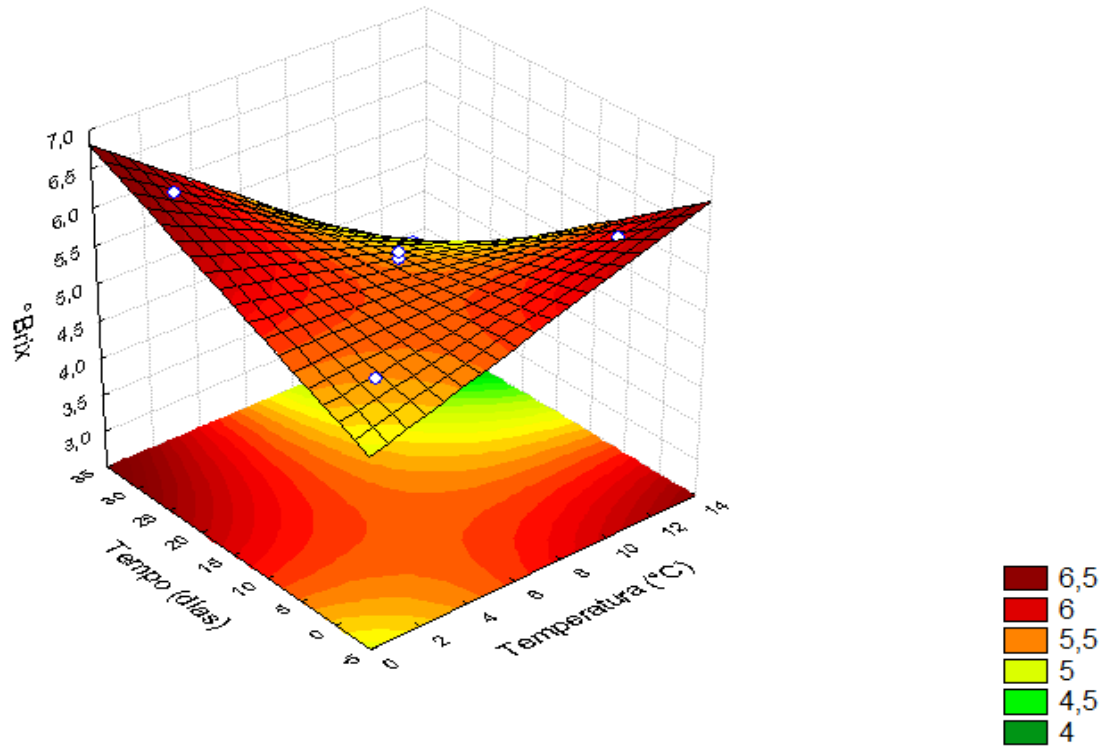

As amostras comercializadas pela indústria B foram também submetidas ao armazenamento, tendo como respostas do planejamento os parâmetros $\mathrm{pH}$, turbidez, condutividade elétrica, teor de sólidos solúveis totais, acidez total, vitamina $\mathrm{C}$ e viscosidade (Tabela 4).

As respostas condutividade elétrica e viscosidade da água de coco comercializada pela indústria B apresentaram o modelo significativo através da Análise de Variância (ANOVA), ou seja, houve influência direta das variáveis de entrada na resposta analisada durante o armazenamento.

O modelo apresentou significância estatística para a resposta condutividade elétrica da água de coco para a indústria $\mathrm{B}$, com coeficiente de determinação, $\mathrm{R}^{2}=96,14 \%$, com a seguinte equação para a Condutividade elétrica $=\mathbf{4 , 3 4 2}$ - 0,010 $X_{1}-\mathbf{0 , 0 1 8} \mathbf{X}_{2}+0,0006 X_{1} X_{2}$. A média e a variável $X_{2}$ foram significativas estatisticamente, com efeito estimado negativo $(-8,39)$ como observado no diagrama de Pareto (Figura 3). A partir do gráfico da superfície de resposta (Figura 4), maiores valores de condutividade elétrica $(4,2$ a 4,4) foram obtidos até o quinto dia do armazenamento, em todas as temperaturas estudadas, enquanto os menores valores desta variável foram observados a partir do décimo quinto dia do armazenamento. De forma geral, observou-se um declínio da condutividade elétrica com o avanço do tempo de armazenamento em todas as temperaturas estudadas.

A variável resposta, viscosidade da água de coco, apresentou coeficiente de determinação de $\mathrm{R}^{2}=99,21 \%$, indicando que o modelo é estatisticamente significativo com equação para Viscosidade $=\mathbf{0 , 3 2 7}-0,001 \mathrm{X}_{1}+0,0014 \mathrm{X}_{2}+$ $\mathbf{0 , 0 0 1 1} \mathbf{X}_{\mathbf{1}} \mathbf{X}_{\mathbf{2}}$. Observa- se que a interação da temperatura e tempo influenciou a viscosidade das águas de coco armazenadas, com o avanço do tempo de armazenamento e maiores temperaturas houve aumento na viscosidade. Assim como, o tempo e temperatura isoladamente também influenciaram o aumento desta variável (Figura 5). A superfície de resposta (Figura 6) correspondente ao modelo ajustado que estabelece a variação da viscosidade em função do tempo e da temperatura de armazenamento da água de coco processada na indústria $\mathrm{B}$. Observa-se que a viscosidade das águas de coco sofreram pequenas variações até o 10 dia de armazenamento em todas as temperaturas estudadas, contudo a partir deste período foi verificado um aumento nesta variável, nas temperaturas superiores a $4{ }^{\circ} \mathrm{C}$ de forma geral maiores valores de viscosidade foram observados em temperaturas superiores a $8{ }^{\circ} \mathrm{C}$ e a partir de 20 dias.

Assim como observado nas amostras de água de coco da indústria $\mathrm{A}$, os parâmetros que não apresentaram o modelo significativo para o planejamento experimental fatorial, ao ser avaliado o comportamento das amostras no armazenamento, apresentaram variações nas respostas avaliadas, assim como o observado para a indústria $\mathrm{A}$. variações na turbidez da água de coco no período de 30 dias de armazenamento foi evidente nos experimentos, assim como diminuição nos valores de $\mathrm{pH}$ com o aumento da temperatura de armazenamento e diminuição nos teores de vitamina $\mathrm{C}$ com o aumento no tempo de armazenamento do produto.

Analisando os gráficos de superfície de resposta, para as variáveis analisadas podemos concluir que a água de coco refrigerada não apresenta vida útil de trinta dias sem que haja perdas sensoriais. A água de coco refrigerada deve ser armazenada em baixas temperaturas por um período máximo de dez dias, sendo este tempo propicio ao consumo humano. 
Suziane Alves Josino Lima et al.

Tabela 4 - Estudo de armazenamento da água de coco comercializada pela indústria B

\begin{tabular}{|c|c|c|c|c|c|c|c|c|c|}
\hline \multirow{3}{*}{ Exp. } & \multicolumn{2}{|c|}{ Variáveis } & \multirow{2}{*}{\multicolumn{7}{|c|}{ Respostas }} \\
\hline & $\begin{array}{c}\text { Temperatura } \\
\left({ }^{\circ} \mathrm{C}\right)\end{array}$ & $\begin{array}{c}\text { Tempo } \\
{[\operatorname{dia}(\mathrm{s})]}\end{array}$ & & & & & & & \\
\hline & $\mathrm{X} 1$ & $\mathrm{X} 2$ & $\mathrm{pH}$ & $\begin{array}{l}\text { Turbidez } \\
\text { (N.T.U) }\end{array}$ & $\begin{array}{l}\text { Condutividade* } \\
\left(\mathrm{mS} / \mathrm{cm}^{-1}\right)\end{array}$ & $\begin{array}{c}\text { SST } \\
\left({ }^{\circ} \text { Brix }\right)\end{array}$ & $\begin{array}{l}\text { ATT (g ác. } \\
\text { Cítrico/100 } \\
\text { mL) }\end{array}$ & $\begin{array}{c}\text { Vit. C } \\
(\mathrm{mg} / 100 \mathrm{~g})\end{array}$ & $\begin{array}{l}\text { Viscosidade* } \\
\left(\mathrm{mm}^{2} / \mathrm{s}^{-1}\right)\end{array}$ \\
\hline 1 & 2 & 1 & $5,30^{\mathrm{a}}$ & $16,70^{\mathrm{c}}$ & 4,20 & $6,30^{\mathrm{b}}$ & $1,30^{\mathrm{c}}$ & $1,10^{\mathrm{ab}}$ & 0,34 \\
\hline 2 & 12 & 1 & $5,20^{\mathrm{a}}$ & $18,10^{\mathrm{c}}$ & 4,20 & $6,20^{\mathrm{b}}$ & $1,20^{\mathrm{c}}$ & $1,20^{\mathrm{a}}$ & 0,34 \\
\hline 3 & 2 & 30 & $5,20^{\mathrm{a}}$ & $68,20^{\mathrm{b}}$ & 3,80 & $6,80^{\mathrm{a}}$ & $1,70^{\mathrm{c}}$ & $0,65^{\mathrm{ab}}$ & 0,43 \\
\hline 4 & 12 & 30 & $3,80^{\mathrm{d}}$ & $271,00^{\mathrm{a}}$ & 3,80 & $4,30^{\mathrm{d}}$ & $11,00^{\mathrm{a}}$ & $0,65^{\mathrm{ab}}$ & 0,78 \\
\hline 5 & 7 & 15 & $4,10^{\mathrm{c}}$ & $25,50^{c}$ & 4,10 & $5,70^{\mathrm{c}}$ & $7,70^{\mathrm{b}}$ & $0,60^{\mathrm{b}}$ & 0,50 \\
\hline 6 & 7 & 15 & $4,10^{\mathrm{c}}$ & $25,40^{\mathrm{c}}$ & 4,10 & $5,50^{\mathrm{c}}$ & $6,70^{\mathrm{b}}$ & $0,60^{\mathrm{b}}$ & 0,45 \\
\hline 7 & 7 & 15 & $4,60^{\mathrm{b}}$ & $26,50^{\mathrm{c}}$ & 4,10 & $5,50^{\mathrm{c}}$ & $7,20^{\mathrm{b}}$ & $0,95^{\mathrm{ab}}$ & 0,47 \\
\hline
\end{tabular}

Médias seguidas por letra distintas, minúsculas nas colunas e maiúsculas nas linhas diferem entre si pelo teste de Tukey (p $\leq 0,05)$. * Resposta em que o modelo se mostrou significativo.

Figura 3 - Diagrama de Pareto para a condutividade elétrica na água de coco armazenada

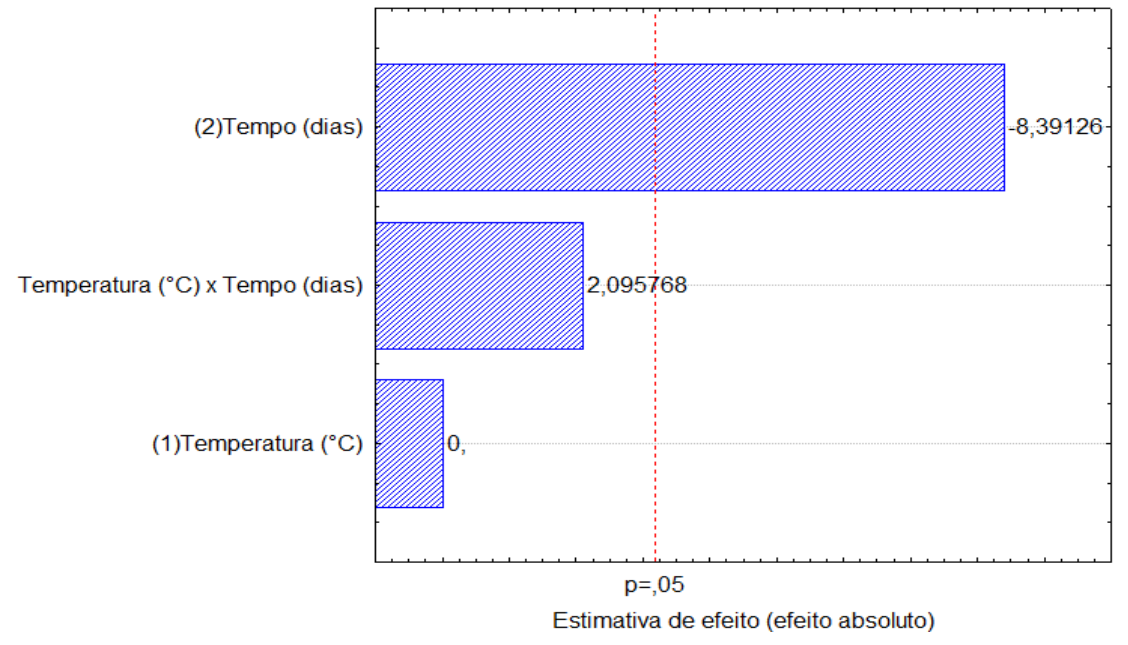

Figura 4 - Superfície de resposta para a variável Condutividade elétrica na água de coco armazenada

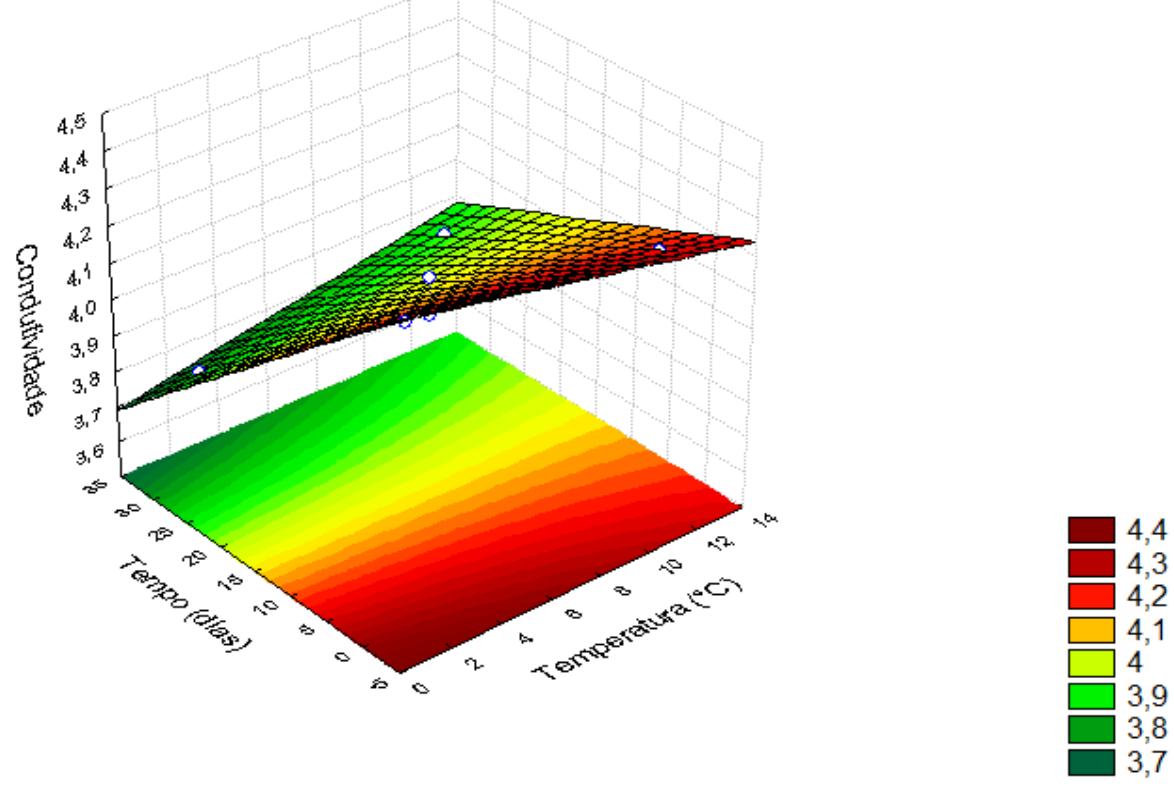


Figura 5 - Diagrama de Pareto para a viscosidade da água de coco armazenada

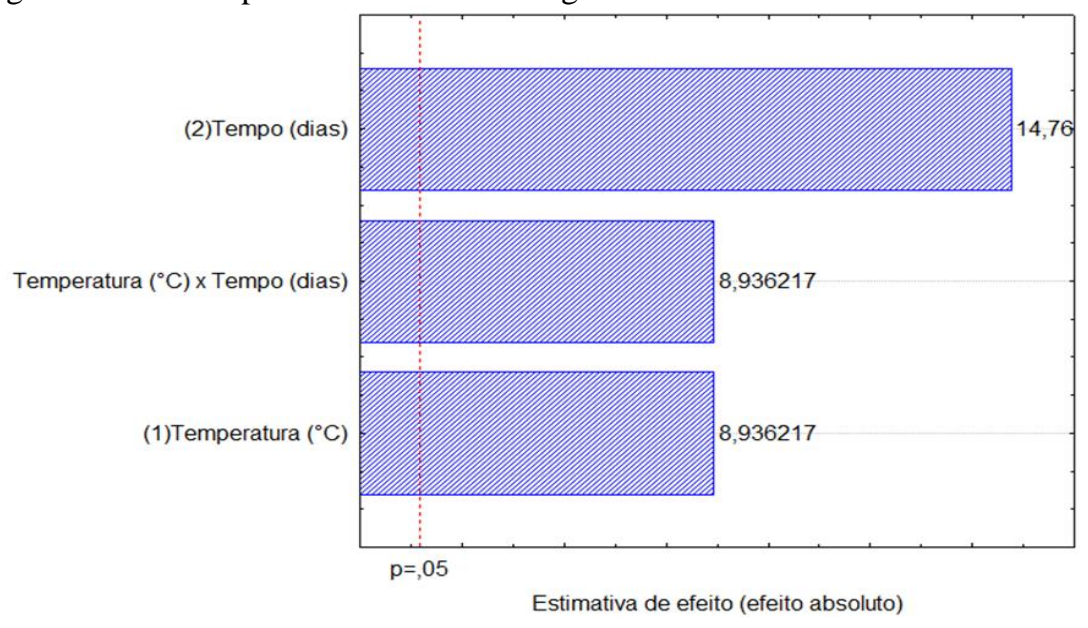

Figura 6 - Superfície de resposta para a variável viscosidade da água de coco armazenada
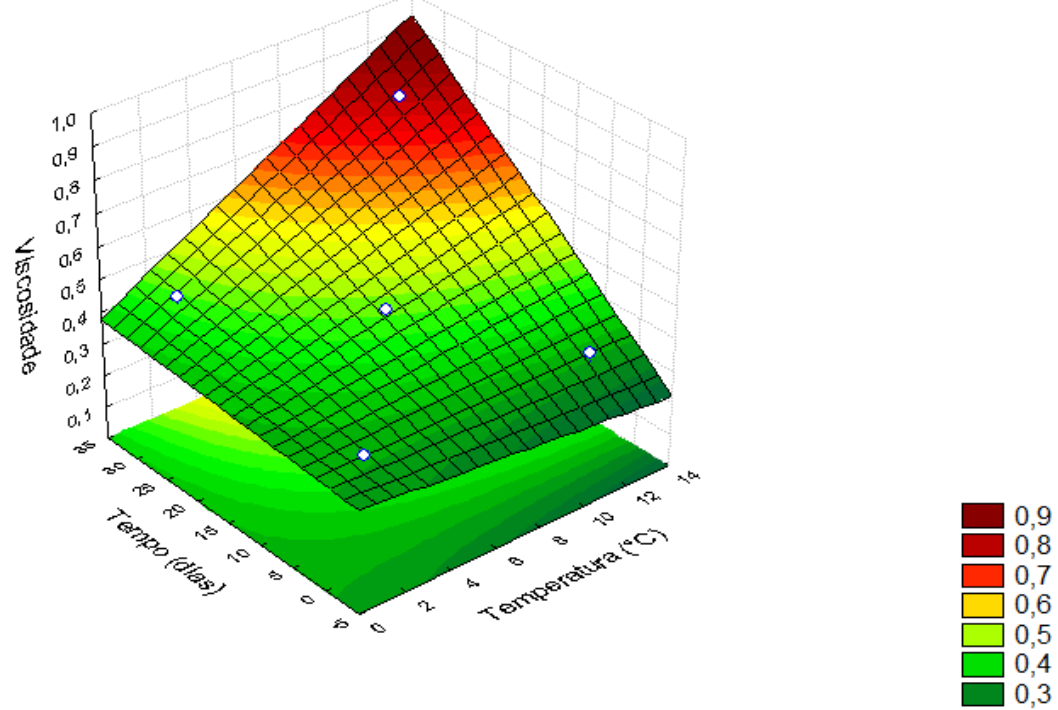

\section{CONCLUSÕES}

De acordo com os resultados podemos concluir que o teor de sólidos solúveis da água de coco para as indústrias $\mathrm{A}$ e B respectivamente, estão, dentro dos padrões estabelecidos pela a legislação em vigência; A viscosidade das águas de coco sofreram pequenas variações até o $10^{\circ}$ dia de armazenamento em todas as temperaturas estudadas; A água de coco refrigerada não apresenta vida útil de trinta dias sem que haja perdas sensoriais no produto; Sugere-se as unidades produtoras a implantação e monitoramento de Boas Práticas de Fabricação de forma a assegurar a qualidade do produto comercializado.

\section{REFERÊNCIAS BIBLIOGRÁFICAS}

AOAC - ASSOCIATION OF OFFICIAL ANALYTICAL CHEMISTS. Official Methods of Analysis.Willians, S (Ed) 14.ed. Arlington, 1997. $1141 \mathrm{p}$.

ARAGÃO, W. M; CRUZ, E. M.; HELVÉCIO, J. S. Caracterização morfológica do fruto e química da água de coco em cultivares de coqueiro anão. Agrotópica, v. 13, n. 2, p. 49-58, 2001.
AROUCHA, E. M. M., SOUZA, C. L. M.; AROUCHA, M. C. M.; VIANNI, R. Características físicas e químicas da água de coco Anão verde e Anão vermelho em diferentes estádios de maturação. Caatinga, Mossoró, v. 18, n. 2, p. 82-87, 2005.

BRASIL. Ministério da Agricultura, Pecuária e Abastecimento. Instrução Normativa $n^{\circ}$ 39, de 22 de Julho de 2009. Aprova o Regulamento Técnico para fixação de identidade e qualidade da água de coco.

BRASIL. Ministério da Saúde. Agência Nacional de Vigilância Sanitária. Métodos químicos e físicoquímicos para análises de alimentos. Instituto Adolfo Lutz. Brasília: Ministério da Saúde, 2008. 1017 p.

CAMPOS, C. F.; SOUZA, P. E. A. COELHO, V.; GLORIA, M. B. A. Chemical composition, enzyme activity and effect of enzyme inactivation on flavour quality of green coconut water. Journal of Food Processing and Preservation, 20, 487-500.1996.

COSTA, L. M. C.; MAIA, G. A.; COSTA, J. C.; FIGUEIREDO, R. W.; SOUSA, P. H. M. Avaliação de água de coco obtida por diferentes métodos de 
conservação. Ciência Agrotécnicas. Lavras, v.29, n, 6, p. 1239-1247, nov./dez., 2005.

EMBRAPA. Evolução da produção de coco no Brasil e o comércio internacional: panorama 2010. Carlos Roberto Martins, Luciano Alves de Jesus Júnior - Aracaju: Embrapa Tabuleiros Costeiros, 2011.

KWIATKOWSKI, A.; OLIVEIRA, D. M.; CLEMENTE, E. Atividade enzimática e parâmetros físico-químicos de água de cocos colhidos em diferentes estádios de desenvolvimento e estação climática. Revista Brasileira de Fruticultura. v. 34, n. 2, Jaboticabal, jun. 2012.

MAGALHÃES, M.P.et al. Conservação de água de coco verde por filtração com membrana. Ciência e Tecnologia de Alimentos, v.25, n. 1, p. 72-77, 2005.

NERY, M.V.S.; BEZERRA, V.S.; LOBATO, M.S.A. Avaliação físico-química de coco-anão cultivado no estado do Amapá. In: XVII Congresso Brasileiro de Fruticultura Brasileira, nov. 2002, Belém-PA. Anais... 1 CD-ROM
OLIVEIRA, R. C.; BARROS, S. T. D.; ROSSI, R. M. Aplicação da metodologia Bayesiana para o estudo reológico da polpa de uva. Revista Brasileira de Produtos Agroindustriais. Campina Grande, 2009. 8 p.

PINHEIRO, A. M.; MACHADO, P. H.; COSTA, J. M. C.; MAIA, G. A.; FERNANDES, A. G.; RODRIGUES; M. C. P.; HERNANDEZ, F. F. H. Caracterização química, físico-química, microbiológica e sensorial de diferentes marcas de água de coco obtidas pelo processo asséptico. Revista Ciência Agronômica, Fortaleza, v. 36, n 2, p. $209-214,2005$.

ROSA, M. F.; ABREU, F. A. P. Processos convencionais de conservação de água-de-coco. In: ARAGÃO, W. M.Coco: pós-colheita. Brasília, DF: Embrapa Informação Tecnológica, 2002. P. 52-53.

SILVA, J. L. A.; DANTAS, F. A. V.; SILVA, F. C. Qualidade microbiológica de águas de coco comercializadas no município de currais Novos/ RN. Revista Holos, n. 25, v. 3, p. 34-35, 2009. 